\title{
A novel non invasive measurement of hemodynamic parameters: Comparison of single-chamber ventricular and dual-chamber pacemaker
}

\author{
Ingrid M. Pardede, Yoga Yuniadi
}

\begin{abstract}
Abstrak
Kami melakukan studi untuk menganalisis parameter hemodinamik pada pacu jantung jenis satu kamar ventrikel dibandingkan dengan jenis dua kamar secara non-invasif dengan thoracic electrical bioimpedance (Physio Flow ${ }^{\mathrm{TM}}$ ). Dilakukan analisis terhadap 48 pasien rawat jalan dengan pacu jantung permanen secara konsekutif, 27 diantaranya dengan pacu jantung jenis satu kamar ventrikel. Diukur parameter jantung: denyut jantung, indeks volume sekuncup, indeks curah jantung, perkiraan fraksi ejeksi, volume akhir diastolik, rasio fungsi awal diastolik, indeks cairan toraks, dan parameter sistemik: indeks kerja jantung kiri, indeks resistensi vaskuler sistemik. Karakteristik dasar dan indikasi pemasangan pacu jantung pada kedua kelompok sama. Penilaian parameter jantung menunjukkan tidak ada perbedaan bermakna pada denyut nadi, indeks volume sekuncup, indeks curah jantung, perkiraan fraksi ejeksi, volume akhir diastolik, indeks cairan thoraks antara kelompok pacu jantung jenis satu kamar ventrikel dengan kelompok pacu jantung jenis dua kamar. Rasio fungsi awal diastolik lebih tinggi bermakna pada pacu jantung jenis satu kamar ventrikel dibandingkan jenis dua kamar: 92\% (10,2$187,7 \%$ ) vs. 100,6\% (48,7-403,2\%); p=0,006. Parameter sistemik menunjukkan indeks kerja jantung kiri pada pacu jantung jenis satu kamar ventrikel lebih tinggi bermakna dibandingkan jenis dua kamar: 4,9 kg.m/m $\left(2,8-7,6 \mathrm{~kg} . \mathrm{m} / \mathrm{m}^{2}\right) \mathrm{vs} .4,3 \mathrm{~kg} . \mathrm{m} / \mathrm{m}^{2}(2,9-7,2$ $\left.\mathrm{kg} . \mathrm{m} / \mathrm{m}^{2}\right) ; p=0,004$. Indeks resistensi vaskular sistemik pada kedua kelompok tidak berbeda bermakna. Pacu jantung jenis satu kamar memberikan manfaat hemodinamik yang setara dengan pacu jantung jenis dua kamar. Pengukuran parameter hemodinamik dengan thoracic electrical bioimpedance mudah diterapkan pada pasien dengan pacu jantung permanen. (Med J Indones 2008; 17: 25-32)
\end{abstract}

\begin{abstract}
We carried out a cross sectional study to analyze hemodynamic parameters of single-chamber ventricular pacemaker compared with dual-chamber pacemaker by using thoracic electrical bioimpedance monitoring method (Physio Flow ${ }^{\mathrm{TM}}$ - a novel simple non-invasive measurement. A total of 48 consecutive outpatients comprised of 27 single chamber pacemaker and 21 dual chamber were analyzed. We measured cardiac parameters: heart rate, stroke volume index, cardiac output index, estimated ejection fraction, end diastolic volume, early diastolic function ratio, thoracic fluid index, and systemic parameters: left cardiac work index and systemic vascular resistance index. Baseline characteristic and pacemaker indication were similar in both groups. Cardiac parameters assessment revealed no significant difference between single-chamber pacemaker and dual-chamber pacemaker in heart rate, stroke volume index, cardiac index, estimated ejection fraction, end-diastolic volume, thoracic fluid index. There was significantly higher early diastolic function ratio in single-chamber pacemaker compared to dual-chamber pacemaker: 92\% (10.2-187.7\%) vs. 100.6\% (48.7-403.2\%); p=0.006. Systemic parameters assessment revealed significantly higher left cardiac work index in single-chamber group than dual-chamber group $4.9 \mathrm{~kg} . \mathrm{m} / \mathrm{m}^{2}\left(2.8-7.6 \mathrm{~kg} . \mathrm{m} / \mathrm{m}^{2}\right)$ vs. $4.3 \mathrm{~kg} . \mathrm{m} / \mathrm{m}^{2}\left(2.9-7.2 \mathrm{~kg} . \mathrm{m} / \mathrm{m}^{2}\right) ; p=0.004$. There was no significant difference on systemic vascular resistance in single-chamber compared to dual-chamber pacemaker. Single-chamber ventricular pacemaker provides similar stroke volume, cardiac output and left cardiac work, compared to dual-chamber pacemaker. A non-invasive hemodynamic measurement using thoracic electrical bioimpedance is feasible for permanent pacemaker outpatients. (Med J Indones 2008; 17: 25-32)
\end{abstract}

Keywords: Permanent pacemaker, single chamber, dual chamber, thoracic electrical bioimpedance, hemodynamic parameter

Permanent pacemakers are implanted to treat or prevent various types of symptomatic bradycardia caused by disorders of cardiac conduction system. ${ }^{1}$ For more than 15 years, there have been two broad types of pacing

Department of Cardiology and Vascular Medicine, Faculty of Medicine, University of Indonesia/National Cardiovascular Center Harapan Kita, Jakarta, Indonesia systems: single-chamber (ventricular) and dual-chamber. The selection of either a single or a dual-chamber pacemaker has clinical and economic implications. ${ }^{2}$ Dual-chamber pacemaker was becoming common for patients who require cardiac pacing. ${ }^{3}$ Dual-chamber pacemaker may confer a physiological advantage over single-chamber pacemaker, as it permit maintenance of atrial ventricular-synchrony. ${ }^{4,5}$ Multiple studies have demonstrated the hemodynamic superiority of 
AV sequential pacing over ventricular pacing. A variety of invasive and non-invasive hemodynamic studies have documented a $10 \%$ to $53 \%$ improvement in cardiac output compared with single-chamber ventricular pacing. Non-invasive studies have failed to predict reliably which patients will derive the greatest benefit from AV synchrony. ${ }^{6}$ However, current invasive and non-invasive measurement techniques were not practical and rather inconvenient for outpatients.

During the past 20 years, cardiac output measurements have become increasingly used, and it probably the most important hemodynamic measurements to asses the patient's perfusion status, because other circulatory measurements may be influenced by other factors or may not be sensitive indicators of hemodynamic deterioration. There are several methods that can be used for cardiac output measurement: invasive technique including Fick oxygen consumption method, dye-dilution method, thermodilution method, and non-invasive technique including Doppler ultrasonography, transthoracic electric bioimpedance-impedance cardiography. ${ }^{7}$ Transthoracic electric bioimpedance-impedance cardiography has been proposed as a simple and readily reproducible noninvasive technique for the determination of cardiac output and intrathoracic fluid content. ${ }^{8}$

We carried out the present study to analyze hemodynamic parameters of single-chamber compared with dual-chamber pacemaker by a simple non invasive method, using thoracic electrical bioimpedance monitoring method. This is the first study based on thoracic electrical bioimpedance method that had performed in our center.

\section{METHODS}

\section{Study design and study population}

A cross sectional study included 48 consecutive patients who admitted to Arrhythmia Outpatient Clinic, National Cardiovascular Center Harapan Kita, Jakarta, in purpose of pacemaker reprogramming, during June - August 2006. We recruited longstanding adult patients whom had undergone permanent pacemaker implantation due to any cardiac conduction system disorder, including single-chamber ventricular pacemaker or dual-chamber pacemaker, have no structural congenital heart disease, clinically in stable condition and cooperative for examination. Singlechamber ventricular pacemaker defines as ventricular pacing that achieved with single lead pacemaker with the only lead in the right ventricular apex or right ventricular outflow tract. Dual-chamber pacemaker defines as device that pace either chamber or both depending on setting, it has leads in right atrium and right ventricle. We hypothesized that single-chamber ventricular pacemaker provides similar hemodynamic outcome compared to dual-chamber pacemaker.

\section{Measurement of hemodynamic parameters and basic principles}

Hemodynamic parameters measured by non-invasive technique, using thoracic electrical bioimpedance method. We used Physio Flow ${ }^{\mathrm{TM}}$ PF-05 Lab 1, software version PF-1.05 which connected to computer's serial port by specific serial RS232 cable. Patients were connected to the equipment by using pre-gelled ECG electrodes $\mathrm{Ag} / \mathrm{AgCl}$. The electrodes were placed on the thorax in the shown positions (Figure 1). Two electrodes (red and orange) were used to monitor ECG in order to measure the heart rate. Four electrodes were used to monitor the impedance signal: white (up) - blue (down) at the base of the neck, lateral triangle of the neck, green (up) - black (down) at xyphoid process. The neck electrodes were put on the other side of pacemaker side. A-10 minutes hemodynamic parameters analysis was performed after calibration on 30 heart beats. During examination, patients were sitting still, limitation on talking or movements. Recorded ECG waveform and impedance signals that displayed on the screen, on schematic shown in Figure 2. Assessment included cardiac parameters: heart rate, stroke volume, cardiac output index, estimated ejection fraction, end diastolic volume, early diastolic function ratio, thoracic fluid index and systemic parameters: left cardiac work index and systemic vascular resistance index.

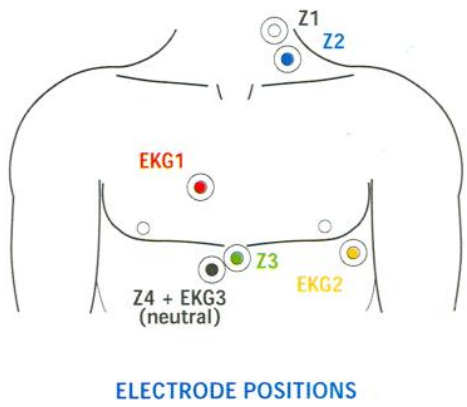

Figure 1. Electrodes position on the thorax and the base of neck. Z1 (white) and Z2 (blue) are electrodes for measuring heart rate. EKG1 (red), Z3 (green), EKG2 (yellow), Z4 + EKG3 (black) are electrodes for monitoring the impedance signal. Black electrode is the neutral electrode. 


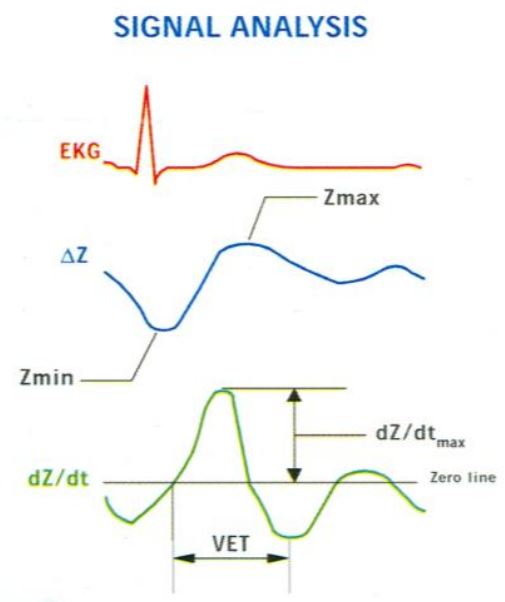

Figure 2. Schematic of signal analysis displayed on computer monitor. Red line represents ECG waveform. Blue line represents $\Delta Z$, thoracic impedance. Green line represents $d Z / d t$, the first derivative of impedance from the impedance. $d \mathrm{Z} / d t$ max represents maximum rate of impedance change during systolic upstroke. $V E T=$ ventricular ejection time.

Thoracic electrical bioimpedance is a non invasive technology that uses computer algorithms to measure pulsatile changes (impedance) in the electrical conductivity of the thorax. The principle of thoracic electrical bioimpedance is that the amount of electrical energy that can flow through of any substance relates to the size (in length and circumference) and the inherent conductivity of that substance. A constant alternating current is passed through the patient's chest and electrical impedance is measured. The change in thoracic blood volume causes changes in impedance between the 8 electrical patches placed on the neck and the thorax of the patient. To measure the electrical conductivity of an object and its impedance, electrical energy of a known, constant voltage is introduced into that object. The amount of voltage is measured at a location (on the object) that is remote from the area where it was introduced. The difference of the amount of voltage between what was introduced and what was measured is an indicator of the impedance to the flow of energy through that object. Changes in impedance over time can be recorded in numeric value and graphed as a waveform similar to and correlated with an electrocardiogram waveform. In order to use this technology to measure the patient's hemodynamic status, baseline thoracic impedance is first established. Baseline impedance provides a measure of thoracic fluid content (the total of the intravascular, interstitial, and intra alveolar fluids). Then, equations built into the bed-side computer are used to calculate various hemodynamic indices from phasic changes in thoracic impedance as they relate to phases in the cardiac cycle. During systole, thoracic blood volume increase while electrical impedance decreases and vice versa. The amount, direction, and timing pulsatile changes on impedance waveform are then measured and computer analyzed to derive values for various cardiac hemodynamic functions. It permits beat-to-beat determination of cardiac output, the product of the amplitude of the first derivative of thoracic impedance signal $(\mathrm{dZ} / \mathrm{dt})$, the ventricular ejection time, and heart rate corrected by the distance between the measuring electrodes. Its use is based on: (1) the dZ/dt signal that originates from the upper thorax; (2) the ventricular ejection period measured by the $\mathrm{dZ} / \mathrm{dt}$ curve that occurs between the opening and closing of the aortic valve; (3) the dZ/dt curve is similar in morphology and timing to the aortic flow curve measured by an electromagnetic flowmeter with a significant linear correlation $(\mathrm{r}=0.9)$ between $\mathrm{dZ} / \mathrm{dt}$ and peak aortic flow; (4) similarity of the linear correlation between stroke volume, determined by the flowmeter and the impedance signal; and (5) significant reduction of the $\mathrm{dZ} / \mathrm{dt}$ signal by $90 \%$ follows simultaneous occlusion of the aorta and the pulmonary artery. The rapid systolic portion of the impedance signal occurs only when blood is ejected into the aorta and is independent of right ventricular ejection. By measuring the maximum rate of change of thoracic impedance during systole, timed from the electrocardiogram, stroke volume is calculated from the product of HR and stroke volume, averaged over 16 cardiac cycles with the SramekBernstein formula. ${ }^{7,9-11}$

\section{Statistical analysis}

Data were analyzed using SPSS software version 15.0. Nominal variable were present as count and percentage. Continues variable were present as median and range. Baseline characteristics and pacemaker indication in both groups were compared using Pearson Chi-Square for dichotomous variables and the MannWhitney $U$ test for continuous variables. A non parametric analysis Mann-Whitney $\mathrm{U}$ test was conducted to compare hemodynamic cardiac and systemic parameters between single-chamber groups and dualchamber group, and comparison hemodynamic parameters on subgroup analysis of double-chamber group. A p value of $<0.05$ was considered statistically significant. 


\section{RESULTS}

A total of 48 consecutive patients comprised of 27 $(56.3 \%)$ with single-chamber ventricular pacemaker and $21(43.8 \%)$ with dual-chamber pacemaker. Time of follow up was ranged from 10 days to 124.6 months (median 13.2 months) since pacemaker placement. Baseline characteristic data are presented in Table 1. Median age of subjects using single-chamber ventricular pacemakers (single-chamber group) was 62 year (range 25 to 75 year). Median age of subjects using dual-chamber pacemaker (dual-chamber group) was 63 year (range 38 to 82 year). There was no difference in age between both groups $(\mathrm{p}=0.38)$. There were more female patients in single-chamber group (55.6\%) compared to dual-chamber group (52.4\%), however there were no significant difference between both groups $(\mathrm{p}=0.82)$. Indication of pacemaker implantation in single-chamber group was respectively due to total atrioventricular block $(55.6 \%)$, sick sinus syndrome $(37 \%)$, sinoatrial node dysfunction-atrioventricular node dysfunction $(3.7 \%)$ and bundle branch block (3.7\%). In dual-chamber group, implantation of pacemaker mostly respectively due to total atrioventricular block (47.6\%), sick sinus syndrome (33.3\%), sinoatrial node dysfunction-atrioventricular node dysfunction $(14.3 \%)$ and bundle branch block (4.8\%). Indications of pacemaker implantation in both groups were homogenous $(\mathrm{p}=0.61)$.
Table 1. Baseline characteristics and pacemaker indication

\begin{tabular}{lccc}
\hline & $\begin{array}{c}\text { Single-chamber } \\
(\mathrm{n}=27)\end{array}$ & $\begin{array}{c}\text { Dual-chamber } \\
(\mathrm{n}=21)\end{array}$ & $\begin{array}{c}\mathrm{P} \\
\text { value }\end{array}$ \\
\hline Age (year) & $62(25-75) \dagger$ & $63(38-82) \dagger$ & 0.38 \\
Female & $15(55.6 \%) \dagger$ & $11(52.4 \%) \dagger$ & 0.82 \\
Indication : & & & \\
- Total AV Block & $15(55.6 \%) \dagger$ & $10(47.6 \%) \dagger$ & \\
- Sick Sinus Syndrome & $10(37 \%)$ & $7(33.3 \%)$ & 0.61 \\
- Sinoatrial \& & $1(3.7 \%)$ & $3(14.3 \%)$ & \\
$\quad$ atrioventricular & $1(3.7 \%)$ & $1(4.8 \%)$ & \\
$\quad$ dysfunction & & & \\
- Bundle Branch Block & & & \\
\hline
\end{tabular}

$\dagger$ Values are given as median (range)

$\$$ Values are given as $n(\%)$

Cardiac parameters assessment of heart rate, stroke volume index, cardiac index, estimation ejection fraction, end diastolic volume, and thoracic fluid index revealed no significant difference between single-chamber group and dual-chamber group, except for early diastolic function ratio- revealed significantly higher value in single-chamber group compared to dual-chamber group. Systemic parameters assessment revealed significantly higher left cardiac work index in single-chamber group than dual-chamber group, however there was no significant difference on systemic vascular resistance index in both groups. Comparison of hemodynamic parameters between single-chamber group and dualchamber group are presented in Table 2.

Table 2. Hemodynamic parameters of single-chamber compared with dual-chamber pacemaker

\begin{tabular}{|c|c|c|c|c|c|}
\hline & \multicolumn{2}{|c|}{ Single-chamber } & \multicolumn{2}{|c|}{ Dual-chamber } & \multirow{2}{*}{$P$ value } \\
\hline & Median & Range & Median & Range & \\
\hline \multicolumn{6}{|l|}{ Cardiac Parameters : } \\
\hline Heart Rate (bpm) & 71.3 & $59.7-113.8$ & 76.7 & $65.6-88.9$ & 0.58 \\
\hline Stroke volume index $\left(\mathrm{ml} / \mathrm{m}^{2}\right)$ & 45.7 & $23-65.9$ & 40.5 & $31.4-56$ & 0.12 \\
\hline Cardiac index $\left(1 / \mathrm{mt} / \mathrm{m}^{2}\right)$ & 3.4 & $2.2-4.9$ & 3.1 & $2.7-3.9$ & 0.053 \\
\hline Estimated Ejection Fraction (\%) & 49.6 & $33.7-62.2$ & 47.3 & $35.4-61.4$ & 0.96 \\
\hline End-diastolic Volume (ml) & 173.9 & $100.4-244.8$ & 141.1 & $98.6-256.7$ & 0.36 \\
\hline Early diastolic function ratio (\%) & 68.6 & $10.2-187.7$ & 34.4 & $25.9-131.3$ & 0.006 \\
\hline Thoracic fluid index (ohm) & 92 & $29.1-129.2$ & 100.6 & $48.7-403.2$ & 0.56 \\
\hline \multicolumn{6}{|l|}{ Systemic Parameters : } \\
\hline Left cardiac work index (kg.m/m²) & 4.9 & $2.8-7.6$ & 4.3 & $2.9-7.2$ & 0.04 \\
\hline $\begin{array}{l}\text { Systemic vascular resistance index } \\
\left(\text { dyn.s. } \mathrm{cm}^{-5} \cdot \mathrm{m}^{2}\right)\end{array}$ & 2307.1 & $1611.7-3673.1$ & 2509.7 & $1861.7-3193.2$ & 0.23 \\
\hline
\end{tabular}


Subgroup analysis on dual-chamber group revealed only $7(33.3 \%)$ with atrial pacing (atrial pacedventricular paced or atrial paced-ventricular sensed) based on ECG. Comparison of hemodynamic parameters between subjects with atrial pacing (A-paced group) and subjects without atrial pacing (non A-paced group) are presented in Table 3. Cardiac parameters assessment of heart rate, stroke volume index, cardiac index, estimation ejection fraction, end diastolic volume, early diastolic function ratio and thoracic fluid index revealed no significant difference between A-paced group and non A-paced group.

\section{DISCUSSION}

We found higher rate of single-chamber ventricular pacemaker implantation than dual-chamber pacemaker in our center. Despite of indication, the selection of pacemaker implantation was also anchored in many factors, such age, sex and cost. However, more recently in other center there is increase dual-chamber pacemaker implantation, since it has been devised that can sense the activity of, and pace both of atrium and ventricle, and thus are able to achieve atrioventricular synchrony, suggest as physiologic pacing. In patients with complete atrioventricular nodal block, dual chamber pacing is superior to ventricular pacing in terms of increasing the heart rate during exercise. ${ }^{12} \mathrm{~A}$ greater proportion of patients with atrioventricular block received dual-chamber pacemakers than did patients with sinus node dysfunction. This is a logical consequence of the initial descriptions of benefit from atrial-tracking systems reported in patients with second- or third-degree atrioventricular block. ${ }^{13}$ In our study populations, the indication of pacemaker implantation mostly due to total atrioventricular block, followed by sick sinus syndrome, sinoatrial and atrioventricular dysfunction, and bundle branch block, respectively. The proportion of the underlying disorders of cardiac conduction system were similar in both groups, however there was higher proportion of sinus node dysfunction in single-chamber ventricular group than in dual-chamber group. We had a contrary result with the evidence, which strongly support atrial based pacing for sinus node disease rather than single chamber-ventricular pacing. This result demonstrated that indication was not the only reason for selection pacemaker mode, cost is one of the considerations of pacemaker mode selection, since single-chamber pacemaker has much less cost than dual-chamber pacemaker.

Most of our study populations in both single-chamber and dual-chamber groups were females, there was similar sex proportion in both groups. Other study showed that men received proportionally more dualchamber pacemakers than women even after control for demographic and clinical characteristics. There are potential explanations that may have a unique application to a pacemaker population. Technical considerations may influence physicians' choices of pacing systems. Dual-chamber pacemakers tend to be larger than ventricular pacemakers. Thus, physicians may have preferred to implant a smaller (singlechamber) pacemaker in smaller patients (women) to avoid the possibility of pacemaker pocket erosion or simply to achieve a better cosmetic result. ${ }^{2,3}$

Table 3. Hemodynamic parameters of atrial pacing compared with non-atrial pacing in dual-chamber pacemaker group

\begin{tabular}{|c|c|c|c|c|c|}
\hline & \multicolumn{2}{|c|}{ A-paced $(n=7)$} & \multicolumn{2}{|c|}{ Non A-paced $(n=14)$} & \multirow{2}{*}{$P$ value } \\
\hline & Median & Range & Median & Range & \\
\hline \multicolumn{6}{|l|}{ Cardiac Parameters : } \\
\hline Heart Rate (bpm) & 79.7 & $65.6-85.6$ & 76.7 & $67.8-88.9$ & 1.0 \\
\hline Stroke volume index $\left(\mathrm{ml} / \mathrm{m}^{2}\right)$ & 38.1 & $33.7-48.2$ & 41.3 & $31.4-56$ & 0.37 \\
\hline Cardiac index $\left(1 / \mathrm{mt}^{2} / \mathrm{m}^{2}\right)$ & 2.9 & $2.7-3.7$ & 3.2 & $2.7-3.9$ & 0.28 \\
\hline Estimated Ejection Fraction (\%) & 52.7 & $44.7-61.1$ & 46.1 & $35.4-61.4$ & 0.14 \\
\hline End-diastolic Volume (ml) & 122.3 & $101.9-158.5$ & 146.3 & $98.6-256.7$ & 0.12 \\
\hline Early diastolic function ratio (\%) & 34.4 & $30-97$ & 37.9 & $25.9-131.3$ & 0.55 \\
\hline Thoracic fluid index (ohm) & 86.1 & $50.3-403.2$ & 103 & $48.7-120.4$ & 0.55 \\
\hline $\begin{array}{l}\text { Systemic Parameters : } \\
\text { Left cardiac work index } \\
\left(\mathrm{kg} \cdot \mathrm{m} / \mathrm{m}^{2}\right)\end{array}$ & 3.9 & $3.3-4.9$ & 4.4 & $2.9-7.2$ & 0.41 \\
\hline $\begin{array}{l}\text { Systemic vascular resistance } \\
\text { index }\left(\text { dyn.s. } \mathrm{cm}^{-5} \cdot \mathrm{m}^{2}\right)\end{array}$ & 2592.2 & $2029.7-2833.1$ & 2343.1 & $1861.7-3193.2$ & 0.37 \\
\hline
\end{tabular}


We found that our study populations were elderly subjects; there was similar median age between both groups. However, advancing age was associated with decreased use of dual-chamber technology. This practice pattern may reflect existing professional guidelines in the United States that emphasize that dual-chamber pacing may be especially indicated in the "active or young patient." ${ }^{1}$ The selection of either a single-chamber or a dual-chamber pacemaker has clinical and economic implications.

Our study found a similar hemodynamic outcome in both single-chamber ventricular and dual-chamber pacemaker. Our study result revealed no superiority of dual-chamber pacemaker over single-chamber pacemaker, particularly on stroke volume index and cardiac index; contrary to previous studies which demonstrated dualchamber pacemaker known physiological and suspected clinical benefits. ${ }^{14-16}$ The rational explanation for this result was downgrade of dual-chamber pacemaker DDDR mode setting (dual chamber rate adaptive pacemaker) to VVI (ventricular demand inhibited) on long-term follow up (median 13.2 months)- in view of the fact that ECG evaluation showed only $33.3 \%$ atrial-paced on DDDR mode pacemaker, the rest showed atrial-sensed ventricular-paced or atrialsensed ventricular-sensed. Previous analyses of DDD (dual-chamber pacing and sensing with inhibition and tracking) pacing mode survival have reported that after 2.5-3.4 years, a total of $4-18 \%$ of patients receiving a DDD pacemaker are downgraded to VVI pacing, most often due to atrial fibrillation (50-75\%) or atrial lead failure (25-35\%). ${ }^{17-20}$ Interestingly, none of our dual-chamber pacemaker subjects were recorded atrial fibrillation and none of atrial lead measurement on follow up indicated an atrial lead failure. Our result showed an early pacemaker downgraded compared to other studies. There is unclear evidence in preventing ventricular pacing in DDDR mode in patients with sick sinus syndrome. Two small studies indicating that a long AV delay is ineffective in preventing ventricular stimulation. $^{21-22}$ Other study demonstrated DDD pacing mode with a fixed long $\mathrm{AV}$ delay reduces pacing in the ventricle in approximately two thirds of patients with SSS, ${ }^{23}$ other study demonstrated during DDD pacing with AV hysteresis, the percentage of ventricular pacing was reduced by as much as $90 \%{ }^{24}$ Our study dual-chamber population showed AV delayed less than $300 \mathrm{~ms}(120-180 \mathrm{~ms})$.

Left ventricular function contribute result of cardiac output on dual-chamber pacing. Previous study comparing cardiac output in patients with dual-chamber pacemaker with normal or depressed left ventricular function revealed cardiac output remained unchanged at difference pacing-rates in patients with LV dysfunction (LVEF $<50 \%$ ). The explanation of this result was the presence of ventricular asynchrony induced by dual-chamber pacing has negative effect on cardiac contractility and did not improve cardiac output at rest or during physical activity in patients with depressed LV function as occurs in those with normal function. ${ }^{25}$ Most of our study population demonstrated LV dysfunction in both groups, this circumstance may contribute hemodynamic outcome in dual-chamber pacemaker that revealed no superiority over singlechamber pacemaker.

There is an inconclusively hemodynamic effect of dual-chamber over single-chamber pacemaker. DDD pacing is associated with some unwanted effects caused by the electrical stimulation in the apex of the right ventricle, namely an asynchronous ventricular activation, contraction and relaxation pattern. This result in decreased systolic and diastolic ventricular function, ${ }^{26-27}$ and some studies have even indicated that chronic pacing in the apex of the right ventricle might be harmful to left ventricular function. ${ }^{28-30}$

Despite of the fact that we demonstrated lower stroke volume index, cardiac index, end diastolic volume, early diastolic function ratio, left cardiac work index, and higher thoracic fluid index, systemic vascular resistance index on dual-chamber pacemaker compared to single-chamber pacemaker, all parameters result that measured were within normal limit. We attempt to find weather atrial pacing in dual-chamber group enhanced hemodynamic outcome, which atrial pacing supposed to be physiological. However, subgroup analysis revealed no significant difference of hemodynamic parameters between atrial pacing and nonatrial pacing, as a result of small sample size.

There is no 'gold standard' method of determining cardiac output, each technique has inherent advantage and disadvantage and merely provides an estimate of cardiac output that is subject to margin of error. ${ }^{7}$ Most studies comparing impedance cardiography results with standard cardiac output determination have shown a correlation of 0.7-0.9. While the accuracy of impedance cardiography remains controversial and can be affected by the inherent limitations of the technique and by low cardiac output, intracardiac shunts, and valvular regurgitation, the high reproducibility of the method is established and may be comparable or superior to other commonly used techniques. When 
accurate determination of cardiac output is crucial, impedance cardiography may be used in conjunction with a standard technique to establish a baseline reference, thereby permitting further analysis. If only the trend need be followed, the high reproducibility of impedance cardiography measurements allows small changes in cardiac output to be detected on a frequent and ongoing basis. ${ }^{11}$ The ease and precision of this technique warrants its more widespread use in the assessment of pacemaker patients. Further use of this promising technique will allow a better definition of its role in the assessment of a wide range of cardiac patients.

It is concluded that impedance cardiography is a simple, precise and non-invasive technique for assessment of pacemaker patients. In contrast, dual-chamber pacing has not shown a significant greater effectiveness on hemodynamic parameters when compared with singlechamber ventricular pacing.

\section{REFERENCES}

1. Dreifus LS, Fisch C, Griffin JC, Gillette PC, Mason JW, Parsonnet V. Guidelines for implantation of cardiac pacemakers and antiarrhythmia devices. A report of the American College of Cardiology/American Heart Association Task Force on Assessment of Diagnostic and Therapeutic Cardiovascular Procedures (Committee on Pacemaker Implantation). Special report. Circulation. 1991; 84:455-467.

2. Lamas GA, Pashos CL, Normand ST, McNeil B. Permanent Pacemaker Selection and Subsequent Survival in Elderly Medicare Pacemaker Recipients. Circulation. 1995; 91:1063-1069.

3. Bernstein AD, Parsonnet V. Survey of cardiac pacing in United States in 1989. Am J Cardiol. 1992; 69:331-338.

4. Montanez A, Hennekens $\mathrm{CH}$, Zebede J, Lamas GA. Pacemaker mode selection: the evidence from randomized trials. Pacing Clin Electrophysiol. 2003;26:1270-1282.

5. Lamas GA, Orav JE, Stambler BS, Ellenbogen KA, Sgarbossa EB, Huang SK, et al. Quality of life and clinical outcomes in elderly patients treated with ventricular pacing as compared with dual chamber pacing. N Engl J Med. 1998;338:1097-1104.

6. Lamas GA, Ellenbogen KA, Hennekens CH, Montanez A. Evidence base for pacemaker selection from physiology to randomized trials. Circulation. 2004;109:443-451.

7. Darovic GO, Graham PG, Pranulis MA. Monitoring Cardiac Output. In: Darovic GO, editor. Hemodynamic monitoring invasive and noninvasive clinical application. $3^{\text {rd }}$ ed. Philadelphia: WB Saunders; 2002. p. 245-261.

8. Cohen A, Frinerman E, Katz M, et al. Validity of bioimpedance hemodynamic measurements during coronary artery bypass grafting (CABG). Isr J Med Sci 1996; 32:966. (Abstract)

9. Engoren M, Barbee D. Comparison of cardiac output determined by bioimpedance, thermodilution, and the Fick method. Am J Crit Care 2005;14:40 - 5.
10. Barry BN, Mallick A, Bodenhama AR, Vucevic M. Lack of agreement between bioimpedance and continuous thermodilution measurement of cardiac output in intensive care unit patients. CritCare 1997;1:71-4.

11. Ovsyshcher I, Furman S. Impedance cardiography for cardiac output estimation in pacemaker patients: review of the literature. Pacing Clin 1993 Jul; 16:1412-22. (Abstract)

12. Kristensson BE, Arnman K, Smedgard P, Ryden L. Physiological versus single rate ventricle pacing: a double blind cross over study. Pacing Clin Electrophysiol 1985; 8:73-84.

13. Kruse I, Arnman K, Conradson T-B, Ryden L. A comparison of the acute and long term hemodynamic effects of ventricular inhibited and atrial synchronous ventricular inhibited pacing. Circulation. 1982;65:846-855

14. Stewart WJ, Dicola VC, Harthorne JW, Gillam LD, Weyman AE. Doppler ultrasound measurement of cardiac output in patients with physiological pacemakers. Am J Cardiol. 1984;54:308-312.

15. Rosenqvist $\mathbf{M}$, Brandt $\mathbf{J}$, Schuller H. Long term pacing in sinus node disease: effects of stimulation mode on cardiovascular morbidity and mortality. Am Heart J 1988;116:16-22.

16. Rosenqvist $M$, Brandt $J$, Schuller $H$. Atrial versus ventricular pacing in sinus node disease: treatment comparison study. Am Heart J 1988;111:292-297.

17. Chamberlain Webber $R$, Petersen ME, Ingram A, Briers L,Sutton R. Reasons for reprogramming dual chamber pacemakers to VVI mode: a retrospective review using a computer database. PACE 1994;17:1730-6.

18. Hummel J, Fazio G, Lawrence J, Walford GD, Brinker JA.The natural history of dual-chamber pacing. PACE 1991;14:1745-7.

19. Gross JN, Moser S, Benedek ZM, Andrews C, Furman S. DDD pacing mode survival in patients with a dualchamber pacemaker. J Am Coll Cardiol 1992;19:1536-41.

20. Ibrahim B, Sanderson JE, Wright B, Palmer R. Dual chamber pacing: how many patients remain in DDD mode over the long term? Br Heart J 1995;74:76-9.

21. Sgarbossa EB, Pinski SL, Wilkoff BL, Castle LW, Trohman RG, Maloney JD. Is programming a long A-V delay efective in permitting spontaneous ventricular activation? (Abstr). PACE 1993;16:872.

22. Nielsen JC, Pedersen AK, Mortensen PT, Thuesen L, Andersen HR. Programming a long AV delay does not prevent ventricular stimulation in patients with SSS and intact AV conduction (Abstr). PACE 1997;20:1574.

23. Nielsen JC, Pedersen AK, Mortensen PT, Thuesen L, Andersen HR. Programming a fixed long atrioventricular delay is not effective in preventing ventricular pacing in patients with sick sinus syndrome. Europace 1999;1:113120.

24. Ector H, Rickards A, Vardas P, Santini M, Sutton R, Stierle U, Kru"ger D, Vincent AM et al. An optimized AV delay algorithm for patients with intermittent atrioventricular conduction. PACE 1998;21:1035-43.

25. Ferroa A, Duilio C, Santomaurob M, Cuocoloa A. Walk test at increased levels of heart rate in patients with dualchamber pacemaker and with normal or depressed left ventricular function. European Heart J 2003;24:21232132. 
26. Leclercq C, Gras D, Le Helloco A, Nicol L, Mabo P, Daubert C. Hemodynamic importance of preserving the normal sequence of ventricular activation in permanent cardiac pacing. Am Heart J 1995;129:1133-41.

27. Rosenqvist M, Bergfeldt L, Haga Y, Ryde'n J, Ryde'n L, Owall A. The effect of ventricular activation sequence on cardiac performance during pacing. PACE 1996;19:127986.

28. Lee MA, Dae MW, Langberg JJ et al. Efects of long-term right ventricular apical pacing on left ventricular perfusion, innervation, function and histology. $\mathrm{J}$ Am Coll Cardiol 1994;24:225-32.

29. Tse H, Lau CP. Long-term efect of right ventricular pacing on myocardial perfusion and function. $\mathrm{J}$ Am Coll Cardiol.1997;29:744-9.

30. Karpawich PP, Justice CD, Cavitt DL, Chang $\mathrm{CH}$. Developmental sequelae of fixed-rate ventricular pacing in the immature canine heart: an electrophysiologic, hemodynamic, and histopathologic evaluation. Am Heart J 1990;119:1077-83. 